\title{
Rare incidence of yolk sac tumor in pregnancy posing management challenge: a case report
}

\author{
${\text { Chanda } \text { Rai }^{1}{ }^{*} \text {, Harsha Shailesh Gaikwad }}^{1}$, Rohini Gupta ${ }^{2}$ \\ ${ }^{1}$ Department of Obstetrics and Gynaecology, ${ }^{2}$ Department of Radiology, VMMC and Safdarjung Hospital, New Delhi, \\ India \\ Received: 01 November 2015 \\ Accepted: 12 December 2015 \\ *Correspondence: \\ Dr. Chanda Rai, \\ E-mail: chanda17.rims@gmail.com \\ Copyright: $\odot$ the author(s), publisher and licensee Medip Academy. This is an open-access article distributed under \\ the terms of the Creative Commons Attribution Non-Commercial License, which permits unrestricted non-commercial \\ use, distribution, and reproduction in any medium, provided the original work is properly cited.
}

\begin{abstract}
Yolk sac tumor of the ovary, although rare but highly malignant, when diagnosed in a pregnant woman is difficult to manage because of risks involved to the fetus but with the advent of surgery and chemotherapy prognosis has greatly improved. A G3P2L2, 35 years old, woman got admitted at 8 months amenorrhea with absent fetal movements since two days with labor pains. She carried an ultrasound report, done at a private clinic which showed intrauterine death of fetus along with a pelvic tumor. Her CT done at our hospital confirmed a pelvic tumor mass posterior to the uterus and in close proximity with the rectum. A laparotomy was planned for her as the pelvic mass was preventing the descent of fetal head thus hindering vaginal delivery. Biopsy from the tumor mass revealed yolk sac tumor of the ovary. Her general condition was poor with low Hb levels and deranged LFT and KFT and was shifted to ICU for intensive care but she could not survive despite the best efforts. Early diagnosis of ovarian yolk sac tumor in pregnancy leads to timely intervention in the forms of surgery and chemotherapy which greatly improves the survival rates.
\end{abstract}

Keywords: Yolk, Pregnant, Tumor, Ovary

\section{INTRODUCTION}

An ovarian malignancy account for 1 in 15,000 to 32,000 pregnancies. ${ }^{1}$ Yolk sac tumor (YST) is a very rare ovarian malignancy in young women. It constitutes $20 \%$ of malignant ovarian germ cell tumors and is the second most common ovarian germ cell tumor. ${ }^{2}$ The commonest germ cell tumor is dysgerminoma which comprises 25 $35 \%$ of all ovarian malignancies. ${ }^{3}$ YST is highly malignant and has a poor prognosis but if detected in early stages, surgery in combination with chemotherapy have shown excellent results and have increased the 5 year survival rate by $87-97 \%{ }^{4}$

\section{CASE REPORT}

35 years, G3P2L2 came at 8 months amenorrhea (LMPnot known) with complaints of absent fetal movements since two days, pain abdomen and bleeding per rectum on and off and loss of appetite for the past one year. There was no history of diarrhoea, constipation, fever, leaking or bleeding per vaginum. She gave history of having been diagnosed with ovarian cancer 11 months back for which she had received 3 cycles of chemotherapy but she had no previous records. She denied any history of malignancy in her family. On general examination, patient had sparse hair growth and appeared pale. Her vitals were stable and there was no lymphadenopathy.

Abdominal examination revealed a single fetus in cephalic presentation with fundal height of 34 weeks and 
mild uterine contractions were felt. On per vaginum examination, cervix was pulled up and deviated to left, os was $\sim 2 \mathrm{~cm}$, early effaced, $7 \times 6 \mathrm{~cm}$ mass was felt in right fornix obliterating the pouch of Douglas, firm to hard in consistency with irregular margins and restricted mobility. Per-rectal examination revealed a breach of $\sim 2$ $\mathrm{cm}$ on anterior rectal wall not communicating with vagina.

Her investigations showed Hb level $-9.5 \mathrm{~g} \%$,TLC- 16,000,

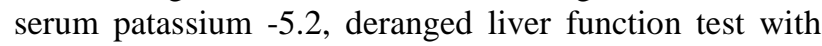
serum bilirubin level of 0.9, SGOT -533, SGPT-533, ALP- 504 and deranged kiney function test with blood urea 85 and serum creatinine level of 1.9. Ultrasound confirmed absent cardiac activity of the fetus. CT abdomen revealed $11 \times 7 \mathrm{~cm}$ well defined ovoid mass caudal to the uterus on right side closely abutting the rectum.

Air foci were seen within the mass raising the possibility of tumor perforating the rectum. Liver was found enlarged with multiple parenchymal masses (largest $\sim 7$ $\mathrm{cm})$, likely to be metastases. Among the tumor markers, serum alpha-fetoprotein was found to be raised.

Since the pelvic mass was preventing the descent of fetal head, laparotomy was done where a macerated stillborn baby was delivered by caesarean section. Multiple liver secondaries were felt in the parenchyma. Left fallopian tube and ovary appeared healthy.

Right ovary was not visualized and right fallopian tube was found adherent to pelvic tumor of around $9 \times 8 \mathrm{~cm}$ lying retroperitoneal with overlying sigmoid colon. Biopsy was taken from the mass and sent for histopathological examination which revealed it to be a case of yolk sac tumor of the ovary.

Omental nodule $\sim 1 \mathrm{~cm}$ was removed. Rest of the peritoneum and intra-abdominal organs appeared normal. Per rectum examination done on OT table showed breach in the anterior rectal wall communicating with peritoneum, so end- colostomy was done and patient was shifted to ICU where she died of sudden cardiorespiratory arrest two days later.

\section{DISCUSSION}

Germ cell tumors are known to arise from primitive germ cells of embryonic gonad. Their peak incidences are seen in women in early 20 s but are known to occur at any age. In children and adolescent more than $60 \%$ tumors are germ cell in origin of which around one-third are malignant.

Yolk sac tumor was first described by Schiller in 1939. Teillum then reclassified the morphological origin 20 years later and called it endodermal sinus tumor. ${ }^{5}$ Yolk sac tumor was so named because of its similarity with extraembryonal yolk sac and vitelline structures. These can occur in pure form or as mixed germ cell tumor. They metastasize early and are very malignant tumors that are radio-resistant but show excellent response to chemotherapy.

This patient had come to us in advanced malignancy with liver parenchymal metastasis indicating stage $4 \mathrm{~b}$ with poor general condition. Had she come at an earlier period of gestation, patient could have undergone a unilateral salpingo-oophorectomy as YSTs are almost always unilateral followed by expectant management as per several case reports. She should then have been kept in close follow-up and in case of recurrences during pregnancy, chemotherapy should be started with etoposide and cisplatin omitting bleomycin since it is known to cause fetal pulmonary fibrosis.

If a patient has already reached 28 weeks and beyond with a salvageable baby, laparotomy can be planned where caesarean section would be followed by staging laparotomy with optimal tumor debulking. These patients would then be subjected to BEP chemotherapy which is known to increase 5 year survival rate by $>80 \%$. Many case reports have followed the mothers and babies with very good results.

Studies have shown that tumor stage significantly affected survival rates. Patients in stage 1 and 2 have favorable prognosis as compared to those with stage 3 and 4. Age is not a significant prognostic factor while determining the treatment outcome.

Our patient was already in stage 4 and could not tolerate the stress of surgery, so could not survive despite our best efforts.

\section{CONCLUSION}

To conclude, although yolk sac tumor is a rare malignancy in pregnancy, it should be kept in mind in all pregnant patients with adnexal mass since prompt action and timely chemotherapy can do wonders for the patient and her baby.

Funding: No funding sources

Conflict of interest: None declared

Ethical approval: Not required

\section{REFERENCES}

1. Zanotti KS, Belinson JL, Kennedy AW. Treatment of gynecologic cancers in pregnancy. Semin Oncol. 2000;27:686-98.

2. Smith HO, Berwick M, Verschraegen CF, Charles $\mathrm{W}$, Letitia L, Muller CY, et al. Incidence and survival rates for female malignant germ cell tumors. Obstet Gynecol. 2006;107(5):1075-85.

3. Bakri YN, Ezzet A, Dohami, Zahrani A. Malignant germ cell tumors of the ovary. Pregnancy considerations. Eur J Obstet Gynecol Reprod Biol. 2000;90:87-91.

4. Williams S, Blessing JA, Liao SY, Ball H, Hanjani H. Adjuvant therapy of ovarian germ cell tumors with cisplatin, etoposide, and bleomycin: a trial of 
the Gynecologic Oncology Group. J Clin Oncol. 1994;12:701-6.

5. Teilum G. Endodermal sinus tumors of the ovary and testis. Comparative morphogenesis of the so-called mesonephroma ovarii (Schiller) and extraembryonic (yolk sac-allantoic) structures of the rat's placenta. Cancer. 1959;12:1092-105.

Cite this article as: Rai C, Gaikwad HS, Gupta R. Rare incidence of yolk sac tumor in pregnancy posing management challenge: a case report. Int $\mathrm{J}$ Reprod Contracept Obstet Gynecol 2016;5:2853-5. 